\title{
Combined application of dexamethasone and hyperbaric oxygen therapy yields better efficacy for patients with delayed encephalopathy after acute carbon monoxide poisoning
}

\author{
This article was published in the following Dove Press journal: \\ Drug Design, Development and Therapy \\ 23 February 2017 \\ Number of times this article has been viewed
}

\author{
Wenping Xiang' \\ Hui Xue ${ }^{2}$ \\ Baojun Wang ${ }^{2}$ \\ Yuechun $\mathrm{Li}^{2}$ \\ Jun Zhang ${ }^{2}$ \\ Changchun Jiang ${ }^{2}$ \\ Furu Liang ${ }^{2}$ \\ Jiangxia Pang ${ }^{2}$ \\ Lehua Yu'
}

'Department of Rehabilitation Medicine, The Second Affiliated Hospital of Chongqing Medical University, Chongqing, ${ }^{2}$ Department of Neurology, Baotou Central Hospital, Baotou, Inner Mongolia, People's Republic of China
Correspondence: Lehua Yu

Department of Rehabilitation Medicine, The Second Affiliated Hospital of Chongqing Medical University, 76 Linjiang Road, 400010 Chongqing, People's

Republic of China

Tel/fax +86 2363093543

Email yulehuaa@yeah.net
Background: Delayed encephalopathy after acute carbon monoxide (CO) poisoning (DEACMP) commonly occurs after recovering from acute CO poisoning. This study was performed to assess the efficacy of the combined application of dexamethasone and hyperbaric oxygen (HBO) therapy in patients with DEACMP.

Patients and methods: A total of 120 patients with DEACMP were recruited and randomly assigned into the experimental group (receiving dexamethasone $5 \mathrm{mg}$ /day or $10 \mathrm{mg}$ /day plus HBO therapy) and control group (HBO therapy as monotherapy). Meanwhile, the conventional treatments were provided for all the patients. We used the Mini-Mental State Examination (MMSE) scale to assess the cognitive function, the National Institutes of Health Stroke Scale (NIHSS) to assess the neurological function and the remission rate (RR) to assess the clinical efficacy. Myelin basic protein (MBP) in the cerebrospinal fluid (CSF) was also measured.

Results: After 4 weeks of treatment, compared to the control group, the experimental group had a significantly higher remission rate $(P=0.032)$, a significantly higher average MMSE score $(P=0.037)$ and a significantly lower average NIHSS score $(P=0.002)$. Meanwhile, there was a trend toward better improvement with dexamethasone $10 \mathrm{mg} /$ day, and the level of MBP in the CSF of patients was significantly lower in the experimental group than in the control group $(P<0.0001)$. The addition of dexamethasone did not significantly increase the incidence of adverse events.

Conclusion: These results indicate that the combined application of dexamethasone and HBO therapy could yield better efficacy for patients with DEACMP and should be viewed as a potential new therapy.

Keywords: hyperbaric oxygen, carbon monoxide, dexamethasone, myelin basic protein

\section{Introduction}

As a colorless, odorless and tasteless gas, carbon monoxide $(\mathrm{CO})$ is very difficult to detect when escaping. A CO concentration of more than $35 \mathrm{ppm}$ will be harmful to human health. ${ }^{1}$ In modern society, $\mathrm{CO}$ poisoning is highly common and results in substantial mortality and morbidity. ${ }^{2}$ Moreover, $\sim 13 \%-50 \%$ of severely CO-poisoned patients who experience coma would suffer from memory impairment, cognitive dysfunction, and behavioral disorders after 2-60 days of incubation. This complication in clinical practice is viewed as delayed encephalopathy after acute CO poisoning (DEACMP)., ${ }^{3,4}$ DEACMP is a disease with poor prognosis and could cause huge economic burden for individuals, families and society. ${ }^{5}$ 
Currently, the pathogenesis of DEACMP is still unclear. ${ }^{6}$ Some researchers believed that it was caused by oxygen deficit. $^{7}$ Other previous studies indicated that DEACMP was associated with the inflammatory reaction in blood vessels, and immune damage..$^{89}$ Chen et $\mathrm{al}^{10}$ reported that the excitatory amino acid might play an important role in the occurrence of DEACMP. Partly due to the unclear pathogenesis, there is still no "gold" standard for the treatment of this disease. Annane et $\mathrm{al}^{11}$ found that hyperbaric oxygen (HBO) therapy was effective in the treatment of patients with acute $\mathrm{CO}$ poisoning. $\mathrm{HBO}$ therapy could increase the blood oxygen in brain tissues, promote the decomposition of carboxyhemoglobin and remove $\mathrm{CO}$ in blood, which could be beneficial for the damaged brain cells to recover. Meanwhile, many researchers also reported that the combined application of HBO therapy and other medications could have a good efficacy for DEACMP treatment, especially in the acute phase. ${ }^{12,13}$ Our previous study found that $N$-butylphthalide and HBO therapy could significantly improve the cognitive dysfunction of patients with DEACMP. ${ }^{1}$

Meanwhile, in an animal experiment, our group also found that dexamethasone could decrease the incidence of DEACMP. ${ }^{14}$ This might be related to the antioxidation and cell protection function of dexamethasone ${ }^{15}$ However, to date, there are few studies investigating the efficacy of dexamethasone in treating patients with DEACMP. Therefore, we conducted this study to assess whether the addition of dexamethasone to HBO therapy could significantly improve the efficacy of HBO therapy as monotherapy. Additionally, a previous study reported that the level of myelin basic protein (MBP) in the cerebrospinal fluid (CSF) of patients with DEACMP was elevated, and moreover it could be a predictive marker of DEACMP. ${ }^{16}$ Our previous study also found an elevated level of MBP in the CO-poisoned rats. ${ }^{17}$ Therefore, we also studied the level of MBP in the CSF of patients with DEACMP.

\section{Patients and methods Recruited patients}

The Institutional Review Board of Baotou Central Hospital reviewed and approved the purpose and design of our work. This clinical trial was performed between July 2014 and August 2016. Patients meeting the following criteria were included: 1) patients who met the criteria of DEACMP; 2) patients with Mini-Mental State Examination (MMSE) score of not more than $24 ;^{18}$ and 3) patients who provided written informed consent. Meanwhile, the following exclusion criteria were used: 1) patients who were allergic to dexamethasone; 2) patients with intellectual impairment; and 3) patients who were pregnant. In total, 120 patients with DEACMP were included.

\section{Experimental methods}

The included patients were randomly assigned into two groups in a 1:1 ratio: the experimental and control groups. We used the random number table to conduct randomization, and the raters and patients were blinded to allocation. The conventional treatments, including using antibiotics, sputum suction, reducing or avoiding respiratory tract infection, maintaining unobstructed airway, maintaining stable blood pressure and blood glucose, regulating water electrolytes, and preventing urinary tract infection, were followed in all patients. At the same time, patients in the two groups were placed in the oxygen chamber with $0.25 \mathrm{MPa}$ absolute pressure for $80 \mathrm{~min} /$ day. ${ }^{1}$ The patients in the experimental group were further randomly assigned into two groups in a 1:1 ratio. Half of the patients received dexamethasone $10 \mathrm{mg} /$ day and the other half received dexamethasone $5 \mathrm{mg} /$ day. The doses of dexamethasone mainly referred to the previous study that used dexamethasone to treat CO-poisoned patients. ${ }^{19}$ The treatment was provided 5 days/week for 4 weeks.

\section{Outcome assessment}

Then, the MMSE score was used to assess the cognitive function and the National Institutes of Health Stroke Scale (NIHSS) was used to assess the neurological function. According to the MMSE score, complete recovery (CR), partial recovery (PR) and no relief (NR) were defined. ${ }^{1}$ The remission rate (RR) was defined by the percentage of $C R$. Meanwhile, we collected the CSF of patients before and after the treatment to study the effect of dexamethasone on the level of MBP. The CSF was collected by lumbar puncture, and the MBP level was measured by enzyme-linked immunosorbent assay (ELISA) technique. The potential adverse events were also recorded and analyzed to assess the acceptability of the combined application of dexamethasone and HBO therapy.

\section{Statistical analysis}

We used mean \pm standard deviation (SD) to show the continuous data in this study. Student's $t$-test and chi-squared test were conducted to assess whether the baseline characteristics were matched. We performed the analysis of covariance (ANCOVA) to assess the effect of the treatment modalities on the posttreatment MMSE and NIHSS scores. ${ }^{1}$ Also, this method was applied to assess the effect of dexamethasone on 
the level of MBP. In this study, the intention-to-treat (ITT) analysis was conducted, and a $P$-value of $<0.05$ was set to be significant.

\section{Results}

\section{Baseline data}

The included 120 patients with DEACMP were randomly assigned into two groups. Each group had 60 patients. In the experimental group, 30 patients received dexamethasone $10 \mathrm{mg} /$ day and the remaining 30 patients received dexamethasone $5 \mathrm{mg} /$ day. The average $\mathrm{CO}$ exposure time in the experimental and control groups was 5.41 hours and 5.22 hours, respectively. In addition, no significant differences in other baseline data, such as age, body mass index (BMI) and carboxyhemoglobin level, were found between the experimental and control groups. The detailed information of the two groups is given in Table 1. Meanwhile, there was no significant difference in the baseline characteristics between patients receiving $5 \mathrm{mg} /$ day and patients receiving $10 \mathrm{mg} /$ day.

\section{MMSE score}

The MMSE scale was assessed at two time points (Figure 1).

Before the treatment, the average MMSE scores between the two groups were similar $(P=0.878)$. After the treatment, the

Table I Demographic characteristics of the included patients

\begin{tabular}{|c|c|c|c|c|}
\hline Variable & Control & Experimental & $t / x^{2}$ & $P$-value \\
\hline Number & 60 & 60 & - & - \\
\hline Female/male & $23 / 37$ & $22 / 38$ & 0.036 & 0.850 \\
\hline Age (years) & $53.5 \pm 11.4$ & $54.1 \pm 12.0$ & 0.428 & 0.603 \\
\hline BMI $\left(\mathrm{kg} / \mathrm{m}^{2}\right)$ & $21.9 \pm 2.8$ & $22.4 \pm 3.3$ & 0.504 & 0.447 \\
\hline $\begin{array}{l}\text { Education level } \\
\text { (years) }\end{array}$ & $10.8 \pm 4.3$ & $11.2 \pm 4.7$ & 0.108 & 0.811 \\
\hline $\begin{array}{l}\text { Work type } \\
(\mathrm{Me} / \mathrm{Ma})\end{array}$ & $33 / 27$ & $40 / 20$ & 1.714 & 0.190 \\
\hline $\begin{array}{l}\mathrm{CO} \text { exposure } \\
\text { time (h) }\end{array}$ & $5.22 \pm 0.72$ & $5.4 I \pm 0.67$ & 0.667 & 0.508 \\
\hline $\begin{array}{l}\mathrm{COHb} \text { levels } \\
(\%)\end{array}$ & $20.7 \pm 13.4$ & $21.3 \pm 12.7$ & 0.374 & 0.257 \\
\hline $\begin{array}{l}\text { WBC count } \\
(n / \mu)\end{array}$ & $|3,8| 7.5 \pm 3,975.3$ & $|3,708.2 \pm 4,02| .3$ & -0.601 & 0.357 \\
\hline LDH (U/L) & $398.3 \pm 205.1$ & $388.2 \pm 221.7$ & -0.208 & 0.607 \\
\hline $\begin{array}{l}\text { Creatine kinase } \\
(\mathrm{IU} / \mathrm{L})\end{array}$ & $4,5 \mid 2.3 \pm 3,857.2$ & $4,504.3 \pm 4,007.0$ & -0.674 & 0.759 \\
\hline Latent phase & $18.9 \pm 8.9$ & $20.3 \pm 9.4$ & 0.527 & 0.387 \\
\hline Hypertension & 7 & 4 & 0.901 & 0.343 \\
\hline Diabetes & 2 & 4 & 0.704 & 0.402 \\
\hline $\begin{array}{l}\text { Coronary heart } \\
\text { disease }\end{array}$ & 6 & 8 & 0.323 & 0.570 \\
\hline
\end{tabular}

Note: Data presented as mean \pm standard deviation or ratio.

Abbreviations: $\mathrm{BMI}$, body mass index; $\mathrm{CO}$, carbon monoxide; h, hours; $\mathrm{COHb}$, carboxyhemoglobin; LDH, lactate dehydrogenase; Me, mental health worker: Ma, manual worker; WBC, white blood cell. average MMSE scores were significantly increased in the experimental $(P<0.0001)$ and control groups $(P<0.0001)$. However, the results of ANCOVA test showed that the two treatment modalities had a significantly different effect on MMSE scores. At the end of the trial, the experimental group had a significantly higher average MMSE score than that of the control group $(P=0.037)$. Furthermore, compared to patients receiving dexamethasone $5 \mathrm{mg} /$ day, patients receiving dexamethasone $10 \mathrm{mg}$ /day had a nonsignificantly higher average MMSE score ( $P=0.204$; Figure 2$)$.

\section{Remission rate}

As shown in Table 2, the MMSE scores of patients in the two groups were not more than 24 before the treatment. But after the treatment, the MMSE scores of 14 patients and 25 patients in the control and experimental groups, respectively, were more than 24 . These patients met the CR criteria. Compared to the control group, the experimental group had a significantly higher RR $(23.3 \%$ vs $41.6 \%, P=0.032)$. Furthermore, compared to patients receiving dexamethasone $5 \mathrm{mg}$ /day, patients receiving dexamethasone $10 \mathrm{mg} /$ day had a nonsignificantly higher $\mathrm{RR}(P=0.432,36.6 \%$ vs $46.6 \%)$.

\section{NIHSS score}

The NIHSS was assessed at two time points (Figure 1). Before the treatment, the average NIHSS scores between the two groups were similar $(P=0.968)$. After the treatment, the average NIHSS scores were significantly decreased in the experimental $(P<0.0001)$ and control groups $(P=0.014)$. However, the results of ANCOVA test showed that the two treatment modalities had a significantly different effect on NIHSS scores. At the end of the trial, the experimental group had a significantly lower average NIHSS score than the control group $(P=0.002)$. Furthermore, compared to patients receiving dexamethasone $5 \mathrm{mg} /$ day, patients receiving dexamethasone $10 \mathrm{mg} /$ day had a nonsignificantly lower average NIHSS score ( $P=0.195$; Figure 2$)$.

\section{MBP level}

The level of MBP in the CSF was measured at two time points (Figure 3). Before the treatment, the level of MBP was not significantly different between the two groups $(P=0.487)$. After the treatment, the levels of MBP in the control group $(P=0.006)$ and experimental group $(P<0.0001)$ were significantly decreased. But the results of ANCOVA test showed that compared to the control group, the experimental group had significantly lower level of MBP $(P<0.0001)$. Furthermore, compared to patients receiving dexamethasone 

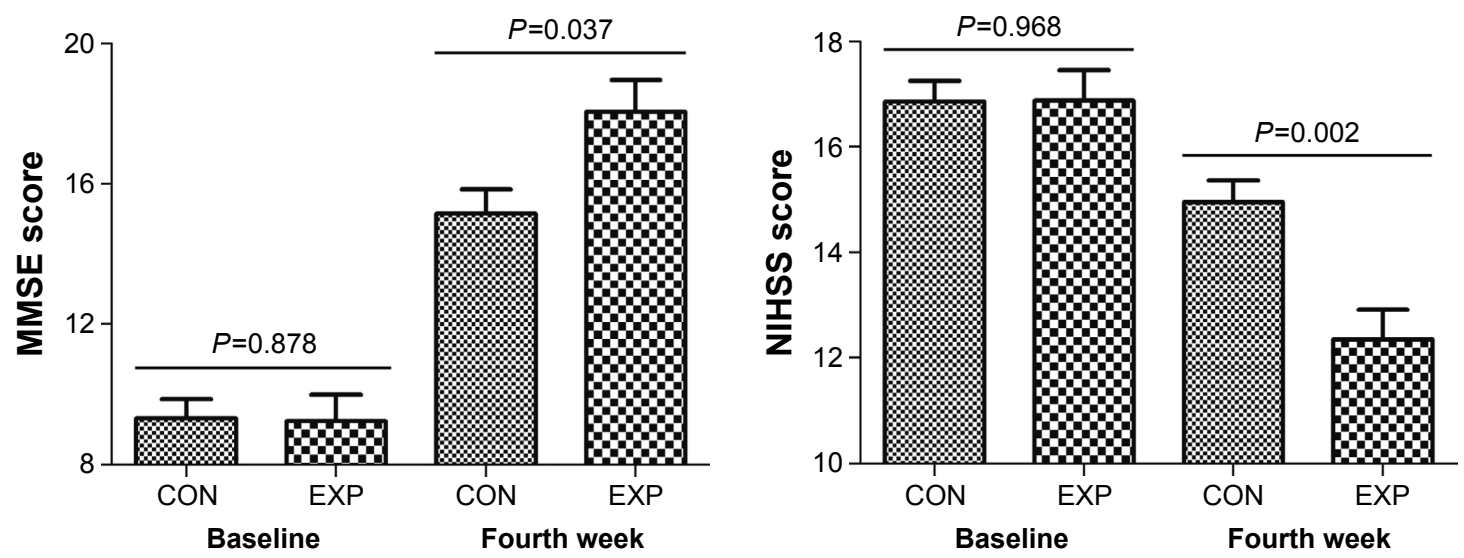

Figure I MMSE and NIHSS scores in the experimental and control groups.

Abbreviations: CON, control; EXP, experimental; MMSE, Mini-Mental State Examination; NIHSS, National Institutes of Health Stroke Scale.

$5 \mathrm{mg} /$ day, patients receiving dexamethasone $10 \mathrm{mg} /$ day had a nonsignificantly lower level of MBP ( $P=0.283$; Figure 3$)$.

\section{Adverse events}

During the whole treatment, no serious adverse events were observed in the two groups, partly because of the short time of taking dexamethasone. No significantly changed blood glucose and blood lipid levels were observed. In the experimental group, two patients had mild nausea, one patient experienced mild vomiting, two patients had loss of appetite, three patients reported mild headache and one patient had mild dizziness. In the control group, one patient had mild nausea, four patients reported mild headache and two patients had loss of appetite. Patients with these adverse events could recover by themselves and did not require special treatment.

\section{Discussion}

In this study, we found that the HBO therapy as monotherapy could significantly increase the MMSE scores and decrease the NIHSS scores of patients with DEACMP after the acutephase treatment, which was consistent with the results in our previous study. ${ }^{1}$ Meanwhile, we found that the addition of dexamethasone could significantly improve the efficacy of HBO therapy. In this study, compared to the control group, the experimental group had significantly higher MMSE scores, higher RR and lower NIHSS scores. Additionally, the addition of dexamethasone did not significantly increase the incidence of adverse events. Therefore, these results demonstrate that the combined application of dexamethasone and HBO therapy could be a potential effective treatment method for patients with DEACMP in the acute-phase treatment. Moreover, we found that there was a trend toward better improvement with dexamethasone $10 \mathrm{mg} /$ day. Because of the limited number of included patients, future studies are needed to verify and support these results.

One point should be noted that the statistical significance is not always equivalent to the clinical significance. Osoba et $\mathrm{al}^{20}$ reported that it was very important to determine the
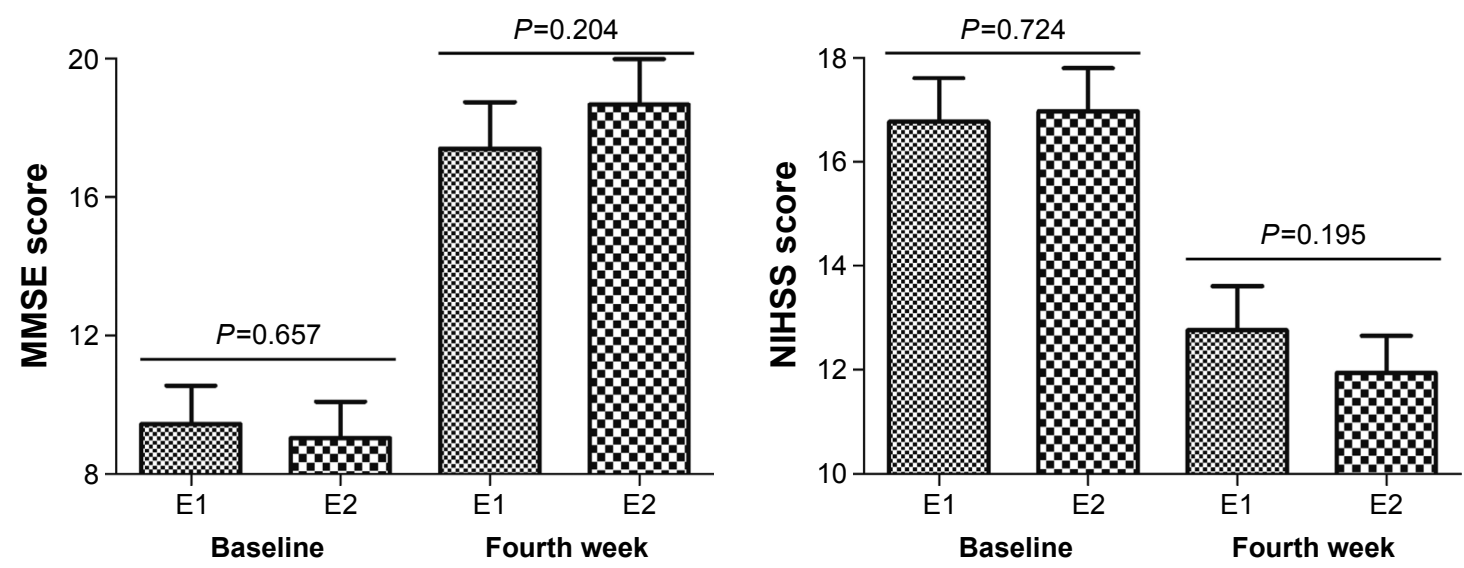

Figure 2 MMSE and NIHSS scores in the dexamethasone $5 \mathrm{mg} /$ day and $10 \mathrm{mg} /$ day groups.

Notes: El, patients receiving dexamethasone $5 \mathrm{mg} /$ day; E2, patients receiving dexamethasone $10 \mathrm{mg} /$ day.

Abbreviations: MMSE, Mini-Mental State Examination; NIHSS, National Institutes of Health Stroke Scale. 
Table 2 RR in the two groups at baseline and end of the fourth week based on MMSE scores

\begin{tabular}{llllllll}
\hline Time & Group & $\mathbf{n}$ & $\mathbf{0 - 9}$ & $\mathbf{1 0 - 2 4}$ & $\mathbf{2 5 - 3 0}$ & $\mathbf{R R}$ & $\boldsymbol{P}$-value \\
\hline Baseline & Control & 60 & 39 & 21 & 0 & - & - \\
& EI & 30 & 18 & 12 & 0 & - & - \\
& E2 & 30 & 20 & 10 & 0 & - & - \\
Fourth week & Control & 60 & 22 & 24 & 14 & $23.3 \%$ & $0.032^{\mathrm{a}}$ \\
& EI & 30 & 7 & 12 & 11 & $36.6 \%$ & $0.432^{\mathrm{b}}$ \\
& E2 & 30 & 2 & 14 & 14 & $46.6 \%$ &
\end{tabular}

Notes: ${ }^{a} P$-value of control vs experimental on RR; ${ }^{b} P$-value of EI vs E2 on RR; $\mathrm{EI}$, patients receiving dexamethasone $5 \mathrm{mg} /$ day; E2, patients receiving dexamethasone $10 \mathrm{mg} /$ day.

Abbreviations: MMSE, Mini-Mental State Examination; RR, remission rate.

clinically meaningful differences, because, in some conditions, the small numerical differences in average scores might result in statistically significant results when the large subjects were used. In this study, we used Cohen's $d$ to assess whether these differences in MMSE scores, NIHSS scores and the level of MBP in the CSF were really clinically meaningful. ${ }^{21}$ The value of Cohen's $d$ more than 0.5 indicated that the effect size was moderate and significant. ${ }^{21}$ In this study, the Cohen's $d$ value was 0.59 on MMSE scores, 0.57 on NIHSS scores and 0.87 on the level of MBP. These results indicated that the combined application of dexamethasone and HBO therapy could yield better clinical efficacy and should be viewed as a potential new therapy for patients with DEACMP.

Atalay et $\mathrm{a}^{22}$ reported that dexamethasone might have effects on brain tissue lipid peroxidation during the treatment of CO-poisoned rats. Another animal study indicated that the early dexamethasone treatment might have a positive effect on preventing DEACMP after 18 days of treatment. ${ }^{23}$ Our previous study found that dexamethasone $30 \mathrm{mg} / \mathrm{kg}$ per day could significantly reduce the mortality of CO-poisoned rats. ${ }^{24}$ Currently, the pharmacological mechanism of dexamethasone is not known. Our previous study found that dexamethasone could attenuate inflammation by protecting myelin sheath from the damage of inflammation response. ${ }^{14}$ As for HBO therapy, it could be beneficial for the damaged brain cells to recover via increasing the blood oxygen in brain tissues. These results indicated that the combined application of HBO therapy and dexamethasone could be effective in treating patients with DEACMP.

Kim et $\mathrm{a}^{25}$ reported that the main pathological lesion of DEACMP was the diffuse white matter demyelination. Another study found that the chemically modified MBP was related to the delayed CO-mediated neuropathology. ${ }^{26}$ Tzakos et $\mathrm{al}^{27}$ reported that MBP played an important role in maintaining the stability of structure and function of myelin sheath in the central nervous system. In this study, we found that the level of MBP was significantly decreased in both groups, but the level was significantly lower in patients receiving dexamethasone. In addition, the high dose of dexamethasone produced more reduction in MBP level. These results might indicate that the HBO therapy and dexamethasone directly or indirectly acted on MBP within the brain to cause the efficacy. Meanwhile, our results indicated that MBP could be a potential predictive marker for DEACMP and an index to estimate whether the treatment modalities were effective for DEACMP. However, future studies are needed to find out whether MBP could be targeted as a pharmacological strategy to prevent delayed encephalopathy.

There were some limitations in our study: 1) the number of patients with DEACMP in each group was relatively small, and we did not conduct the sample size calculation; 2 ) in this study, we only assessed the efficacy of dexamethasone and HBO therapy in the acute-phase treatment of DEACMP; hence, future studies are needed to assess its
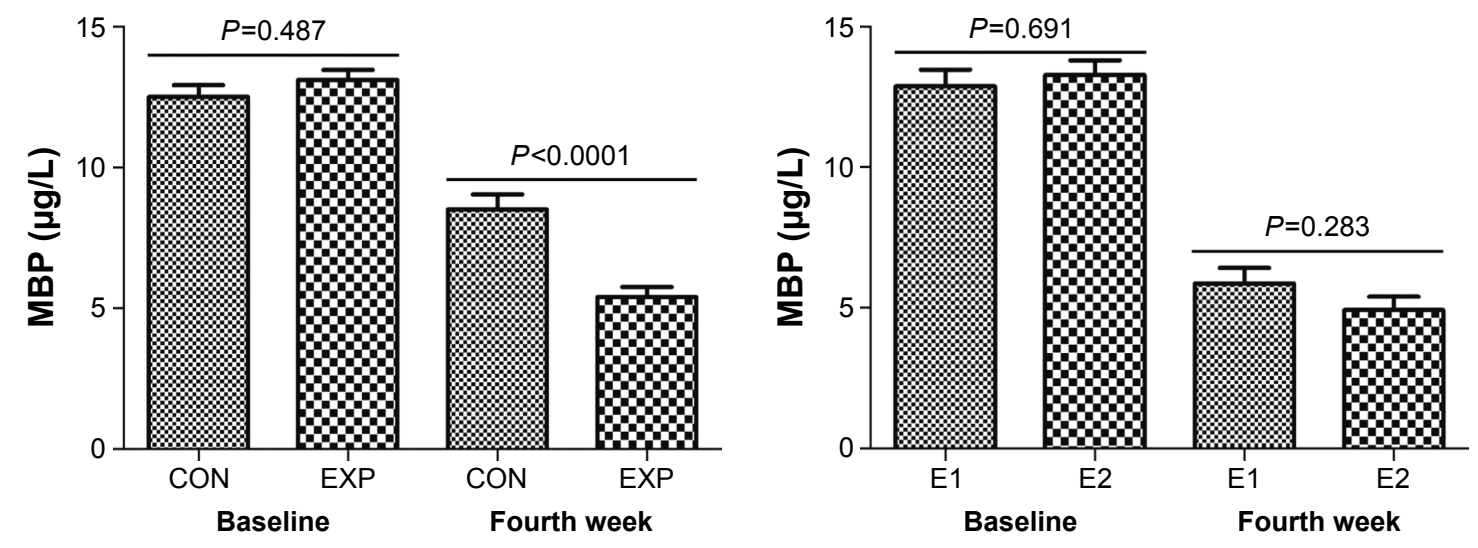

Figure 3 The level of MBP in CSF of patients with DEACMP.

Notes: EI, patients receiving dexamethasone $5 \mathrm{mg} /$ day; E2, patients receiving dexamethasone $10 \mathrm{mg} /$ day.

Abbreviations: CO, carbon monoxide; CON, control; CSF, cerebrospinal fluid; DEACMP, delayed encephalopathy after acute CO poisoning; EXP, experimental; MBP, myelin basic protein. 
long-term efficacy; 3) it would have been better to randomize the recruited patients into three groups (control, E1 and E2) from the start rather than randomize into two groups (control and experimental) and then splitting off the experimental; 4) all the patients in our study were from the same city, which might limit the applicability of our findings. ${ }^{28}$ Finally, a significant difference in efficacy between the high- and low-dose dexamethasone was not found in this study; future studies are needed to determine the optimal dose.

\section{Conclusion}

Our study found that the combined application of dexamethasone and HBO therapy could yield better efficacy for patients with DEACMP than HBO therapy as monotherapy. Compared to dexamethasone $5 \mathrm{mg}$ /day, the efficacy of dexamethasone $10 \mathrm{mg}$ /day had a tendency to be better. Meanwhile, the level of MBP in the CSF was significantly decreased in both groups after the treatment. Because this study was limited by the small sample size, future studies are needed to verify and support our findings.

\section{Acknowledgment}

Sincere gratitude is extended to the nurses in our department and participants for their efforts and cooperation.

\section{Disclosure}

The authors report no conflicts of interest in this work.

\section{References}

1. Wang B, Xiang W, Xue H, et al. Efficacy of N-Butylphthalide and hyperbaric oxygen therapy on cognitive dysfunction in patients with delayed encephalopathy after acute carbon monoxide poisoning. Med Sci Monit. Epub 2016.

2. Hampson NB, Piantadosi CA, Thom SR, Weaver LK. Practice recommendations in the diagnosis, management, and prevention of carbon monoxide poisoning. Am J Respir Crit Care Med. 2012;186(11):1095-1101.

3. Goldstein M. Carbon monoxide poisoning. J Emerg Nurs. 2008;34(6): $538-542$.

4. Hsiao CL, Kuo HC, Huang CC. Delayed encephalopathy after carbon monoxide intoxication-long-term prognosis and correlation of clinical manifestations and neuroimages. Acta Neurol Taiwan. 2004;13:64-70.

5. Hu H, Pan X, Wan Y, Zhang Q, Liang W. Factors affecting the prognosis of patients with delayed encephalopathy after acute carbon monoxide poisoning. Am J Emerg Med. 2011;29(3):261-264.

6. Hara S, Mukai T, Kurosaki K, Mizukami H, Kuriiwa F, Endo T. Role of nitric oxide system in hydroxyl radical generation in rat striatum due to carbon monoxide poisoning, as determined by microdialysis. Toxicology. 2007;239(1):136-143.

7. Gorman D, Lin HY, Williams C. Early evidence of a regulated response to hypoxaemia in sheep that preserves the brain cortex. Neurosci Lett. 2006;394(3):174-178.

8. Wang W, Li J, Chang Y, et al. Effects of immune reaction in rats after acute carbon monoxide poisoning. Undersea Hyperb Med. 2011; 38(4):239.
9. Thom SR, Bhopale VM, Han ST, Clark JM, Hardy KR. Intravascular neutrophil activation due to carbon monoxide poisoning. Am J Respir Crit Care Med. 2006;174(11):1239-1248.

10. Chen M, Lu TJ, Chen XJ, et al. Differential roles of NMDA receptor subtypes in ischemic neuronal cell death and ischemic tolerance. Stroke. 2008;39(11):3042-3048.

11. Annane D, Chadda K, Gajdos P, Jars-Guincestre MC, Chevret S, Raphael JC. Hyperbaric oxygen therapy for acute domestic carbon monoxide poisoning: two randomized controlled trials. Intensive Care Med. 2011;37(7):486-492.

12. Lo CP, Chen SY, Chou MC, et al. Diffusion - tensor MR imaging for evaluation of the efficacy of hyperbaric oxygen therapy in patients with delayed neuropsychiatric syndrome caused by carbon monoxide inhalation. Eur J Neurol. 2007;14(7):777-782.

13. Prockop LD, Chichkova RI. Carbon monoxide intoxication: an updated review. J Neurol Sci. 2007;262(1):122-130.

14. Xiang WP, Xue H, Wang BJ. Delayed encephalopathy of acute carbon monoxide intoxication in rats: potential mechanism and intervention of dexamethasone. Pak J Pharm Sci. 2014;27(6 suppl):2025-2028.

15. Rocksén D, Lilliehöök B, Larsson R, Johansson T, Bucht A. Differential anti-inflammatory and anti-oxidative effects of dexamethasone and $\mathrm{N}$-acetylcysteine in endotoxin-induced lung inflammation. Clin Exp Immunol. 2000;122(2):249-256.

16. Ide T, Kamijo Y. Myelin basic protein in cerebrospinal fluid: a predictive marker of delayed encephalopathy from carbon monoxide poisoning. Am J Emerg Med. 2008;26(8):908-912.

17. Xiang WP, Zhang F, Xue H, et al. Mechanism of delayed encephalopathy in acute carbon monoxide poisoning rats and mouse nerve growth factor in early intervention. Chin Pharm J. 2013;48(24): 2123-2127.

18. Shu AH, Wang Q, Chen XB. Effect of different depths of anesthesia on postoperative cognitive function in laparoscopic patients: a randomized clinical trial. Curr Med Res Opin. 2015;31:1883-1887.

19. Ma XY. Clinical study of large dose of dexamethasone combined with hyperbaric oxygen in treatment of acute carbon monoxide poisoning. Med Innov China. 2013;10(23):045-047.

20. Osoba D, Rodrigues G, Myles J, Zee B, Pater J. Interpreting the significance of changes in health-related quality-of-life scores. J Clin Oncol. 1998;16(1):139-144.

21. Sawilowsky S. New effect size rules of thumb. J Mod Appl Stat Methods. 2009;8(2):467-474.

22. Atalay H, Aybek H, Koseoglu M, et al. The effects of amifostine and dexamethasone on brain tissue lipid peroxidation during oxygen treatment of carbon monoxide-poisoned rats. Adv Ther. 2006;23(2): 332-341.

23. Li Q, Song JJ, Zhang HY, Fu K, Lan HB, Deng Y. Dexamethasone therapy for preventing delayed encephalopathy after carbon monoxide poisoning. Biotech Histochem. 2015;90(8):561-567.

24. Xiang WP, Li QY, Xue H, et al. The predictive value of myelin basic protein in rats with the final outcome of carbon monoxide poisoning and the dexamethasone intervention function. J Brain Nerv Dis. 2014;22(5):344-346.

25. Kim JH, Chang KH, Song IC, et al. Delayed encephalopathy of acute carbon monoxide intoxication: diffusivity of cerebral white matter lesions. AJNR Am J Neuroradiol. 2003;24(8):1592-1597.

26. Thom SR, Bhopale VM, Fisher D, Zhang J, Gimotty P. Delayed neuropathology after carbon monoxide poisoning is immune-mediated. Proc Natl Acad Sci U S A. 2004;101(37):13660-13665.

27. Tzakos AG, Troganis A, Theodorou V, et al. Structure and function of the myelin proteins: current status and perspectives in relation to multiple sclerosis. Curr Med Chem. 2005;12(13):1569-1587.

28. Chen J, Zhou C, Liu Z, et al. Divergent urinary metabolic phenotypes between major depressive disorder and bipolar disorder identified by a combined GC-MS and NMR spectroscopic metabonomic approach. J Proteome Res. 2015;14(8):3382-3389. 
Drug Design, Development and Therapy

Dovepress

\section{Publish your work in this journal}

Drug Design, Development and Therapy is an international, peerreviewed open-access journal that spans the spectrum of drug design and development through to clinical applications. Clinical outcomes, patient safety, and programs for the development and effective, safe, and sustained use of medicines are the features of the journal, which

has also been accepted for indexing on PubMed Central. The manuscript management system is completely online and includes a very quick and fair peer-review system, which is all easy to use. Visit http://www.dovepress.com/testimonials.php to read real quotes from published authors.

Submit your manuscript here: http://www.dovepress.com/drug-design-development-and-therapy-journal 